\title{
Enhancing the liquid phase exfoliation of graphite in both aqueous and organic mixtures
}

\author{
a,* M.P. Lavin-Lopez, a J.L. Valverde, a L.M. Dominguez-Delgado, a L. Sanchez-Silva and a A. \\ Romero
}

a Department of Chemical Engineering, University of Castilla-La Mancha, Avenida Camilo José Cela 12, Ciudad Real, Spain, 13071

\section{ABSTRACT}

Two different solvent mixtures, aqueous and organic, were used in the graphite liquid phase exfoliation. These solvent mixtures were selected through a detailed study of Hansen Solubility Parameters. Different operational sonication parameters (sonication temperature, cycle, amplitude and time) were studied in order to analyze their influence over the exfoliation process. Exfoliated graphite obtained after different sonication conditions were further characterized by RAMAN spectroscopy and thermogravimetric techniques. Obtained results showed that, among all the studied sonication parameters, time is the most important one due to its influence over characteristics of the final exfoliated product. Thus, it was evidenced the defect formation at higher sonication times, being dominant the growth of bulk defects in the structure of exfoliated samples at sonication times superior to 5 hours. As consequence, a careful tuning of the sonication parameters is necessary in order to obtain exfoliated samples with low disorder.

Keywords: Graphite, exfoliation, Hansen Solubility Parameters, aqueous solvents, organic solvent.

*Correspondence to Author:

M.P. Lavin-Lopez

Department of Chemical Engineering, University of Castilla-La Mancha, Avenida Camilo José Cela 12, Ciudad Real, Spain, 13071

How to cite this article:

M.P. Lavin-Lopez et al., ENHANCING THE LIQUID PHASE EXFOLIATION OF GRAPHITE IN BOTH AQUEOUS AND ORGANIC MIXTURES.. International Research Journal of Materials Sciences and Applications, 2017; 1:5.

\section{eSciencePublisher。}

eSciPub LLC, Houston, TX USA. Website: http://escipub.com/ 


\section{Introduction}

Recently, a single atomic layer of $\mathrm{sp}^{2}$-bonded carbon atoms package, in a two dimensional crystal structure material called graphene, has gained the attention of researchers all over the world due to its remarkable properties which makes it the profitable material for a wide variety of applications ${ }^{1}$. Two different strategies can be follow to synthesize graphene: Bottom-Up and Top Down. The first one is known as selfassembly or growth strategy. It starts from a nanometric molecular structure which becomes bound to each other to increase the size of the structure. The main idea of the second one, is based on start the synthesis process from a larger material and reduce it gradually, so it is passed from macro to nano size materials. In the Bottom-Up strategy, a carbonaceous gas is used to synthesize graphene over a substrate whereas, in the Top Down strategy, graphite is used as raw material to reach the desired product 2 . Among the different synthesis methods included in the Top-Down strategy, liquid-phase exfoliation of graphite using ultrasound, is considered a promised one to synthesize graphene in large quantities 3, 4, 5, 6 . Ultrasound allows the direct exfoliation of graphite in organic solvents, aqueous solutions (with or without surfactants) or ionic liquids. The main advantages of this method are the absence of oxidative processes, the low operating temperatures and the absence of subsequent treatment processes ${ }^{7}$.

Layered materials are characterized by weak Van der Waals attractions between adjacent layers that let them slide on each other. The attraction between them is strong enough to allow a complete exfoliation into individual layers 7. Ultrasonic liquid exfoliation, allows breaking these weak bonds between adjacent layers to produce individual nanosized layers, transforming graphite into exfoliated graphite. During sonication, ultrasound form cavitation inducing a shearing force on graphite, resulting in its exfoliation ${ }^{3}$. Thus, solvent-graphene layers interactions have to balance the inter-sheets

$$
R_{a}=\left[4 \cdot\left(\delta_{D_{\text {solvent }}}-\delta_{D_{\text {solute }}}\right)^{2}+\left(\delta_{P_{\text {solvent }}}-\delta_{P_{\text {solute }}}\right)^{2}+\left(\delta_{H_{\text {solvent }}}-\delta_{H_{\text {solute }}}\right)^{2}\right]^{1 / 2}
$$

A decrease in $R_{a}$ parameter means a significant increase in solubility ${ }^{17}$. attractive forces. Moreover it is crucial that, once exfoliated, graphene sheets do not experiment re-aggregation. Hence the necessity for significantly reduce the interfacial tension and so, minimizes the area of the graphene surfaces in contact ${ }^{7}$. With this in mind, it is clear that, a suitable solvent with surface tension to adequately disperse graphite and graphene and minimize the interfacial tension is required ${ }^{8}$. It has been found that, organic solvents like $\mathrm{N}$ Methylpyrrolidone (NMP) $\quad 9 \quad$ or Dimethylformamide (DMF) ${ }^{10}$ are commonly used to obtain high quality graphene by graphite exfoliation. Unfortunately, the most suitable solvents are usually toxic and have high boiling points, which hinder their disposal ${ }^{11}$. In this sense, problems of toxicity associated with organic solvents can be overcome by using aqueous solutions ${ }^{12}$. However, graphene sheets have hydrophobic character and therefore, the presence of surfactants/stabilizers are required to avoid the stacking of graphene produced during exfoliation ${ }^{13}$. Here, surfactant assisted exfoliation plays a significant role, because surfactants (e.g. small organic molecules acting surface stabilizers) can stabilize exfoliated graphene sheets not only in water but also in organic solvents. A suitable surfactant (regardless of whether they are used with aqueous 4, 6, 14 or organic solvents $3,6,15,16$ ) should have a good affinity, be miscible and therefore be able to adequately solubilize the solute.

Hansen Solubility Parameters (HSP), have proven to be a powerful and practical way to understand issues of solubility, dispersion, diffusion, chromatography and more. The key insight is that solvents, polymers, nanoparticles etc. can be well characterized by just three parameters: $\delta_{H}, \delta_{D}, \delta_{P}$. They correspond with the forces due to the links of hydrogen bonds, dispersion forces and intermolecular forces, respectively. These parameters considered a three dimensional space called HSP ${ }^{17}$. In the Hansen space, between solvent and solute, HSP distance $\left(R_{a}\right)$ is defined as:

In the case of binary mixture (solvent 1 and solvent 2), HSP is proportional to the volume fraction of the component solvent of the mixture 18. 


$$
\delta_{i, \text { mix }}=\frac{\left[\frac{1-\emptyset_{\text {solvent } 1}}{\rho_{\text {solvent } 2} \cdot \delta_{i, \text { solvent } 2}}+\frac{\emptyset_{\text {solvent } 1}}{\rho_{\text {solvent } 1} \cdot \delta_{i, \text { solvent } 1}}\right]}{\frac{1-\emptyset_{\text {solvent } 1}}{\rho_{\text {solvent } 2}+\frac{\emptyset_{\text {solvent } 1}}{\rho_{\text {solvent } 1}}}}
$$

Where i denotes $\mathrm{D}, \mathrm{H}$ or $\mathrm{P}, \varnothing$ represents the solute mass fraction and $\rho$ the solute density. A more sophisticate model within the HSP theory relates the mixture enthalpy and the solute concentration, in order to know the most suitable mass fraction of each solvent in binary mixtures. Taking into account that graphene is the solute,

$$
\tau_{G}=e^{\left[-\left(\delta_{D, \text { mixture }}-\delta_{D, \text { solute }}\right)^{2}-\frac{1}{4}\left(\delta_{P, \text { mixture }}-\delta_{P, \text { solute }}\right)^{2}-\frac{1}{4}\left(\delta_{H, \text { mixture }}-\delta_{H, \text { solute }}\right)^{2}\right]}
$$

Thus, the graphene dispersion tendency in a binary mixture can be predict by using the HSP theory ${ }^{18}$.

The first time graphite exfoliation was achieve was in 2010 by Khan et al. ${ }^{15}$ which required around 500 hours to obtain high quality graphene. Recent studies have shown that, to achieve the same goal using aqueous solutions, sonication times between $3{ }^{19}$ and 24 hours ${ }^{20}$ were required, while in the case of organic solutions, sonication times usually not excess 6 hours ${ }^{21}$. Still, it is necessary to consider that, sonication time required to exfoliate graphite, largely depends on the nature and concentration of solvent used.

Typically, graphite sonication is a nondestructive process and, in general its duration does not cause destructive problems in graphene layers (defects are usually located at the edge of the graphene layers, being the basal plane free of defects). However, excessive sonication times, could produce the breakage of the edges of the graphene sheets, thereby reducing flakes size and, as consequence, defects which could be considered as basal ones ${ }^{7}$.

In this manuscript, two different solvent mixtures, both aqueous and organic ones, were used in the graphite liquid phase exfoliation. These solvent mixtures were selected through a detailed study of Hansen Solubility Parameters. Different operational sonication parameters (sonication temperature, cycle, amplitude and time) were studied in detail in order to analyze their influence over the exfoliation process. Exfoliated graphite obtained after the study of the different sonication conditions were further the solute concentration $(\Gamma \mathrm{G})$ is similar to that obtained for CNTs ${ }^{18}$. By using the mixture enthalpy defined by Hansen ${ }^{17}$ and, considering a very low volume fraction of dispersed graphene, the dispersion concentration of solute can be defined as:

characterized by RAMAN spectroscopy and thermogravimetric techniques.

\section{Experimental:}

\subsection{Materials:}

Graphite powder, with a particle size $<20 \mu \mathrm{m}$, was supplied by Sigma Aldrich. Acetone (purity $>99 \%$ ), 1-Butanol (purity > 96\%) were supplied by Panreac and 2-Butanol (purity $>99 \%$ ) was supplied by Sigma-Aldrich.

\subsection{Graphite exfoliation process:}

Graphite exfoliation was performed by sonicating 25 grams of graphite in the presence of 1 liter of organic solvent mixture (1-Butanol $50 \% \mathrm{v} / \mathrm{v}$ and 2 -Butanol $50 \% \mathrm{v} / \mathrm{v}$ ) or aqueous solvent mixture (Water/Acetone $75 \% \mathrm{v} / \mathrm{v}$ ). This process involved three different steps: graphite dispersion in the solvent, exfoliated graphite purification to remove any remaining solvent used during the exfoliation and, sample drying.

Graphite exfoliation was carried out in a cooling jacketed glass reactor. A sonicator (HIELCHER UP400S, 400W, $24 \mathrm{kHz}$ ) was introduced inside the reactor and, the experiments were carried out by varying different sonication parameters that could influence over graphite exfoliation (sonication amplitude (0-100\%), sonication cycle $(0-1)$, sonication time $(2.5 \mathrm{~h}-48 \mathrm{~h})$ and sonication temperature $\left(15^{\circ} \mathrm{C}-30^{\circ} \mathrm{C}\right)$ ). Finally, obtained product was filtrated under vacuum conditions to remove the solvent, by using a 20-40 $\mu \mathrm{m}$ filter. The resulting cake was washed with $100 \mathrm{ml}$ of deionized water to remove any remaining solvent and thus, avoid any vapors in the drying step (100드. overnight).

\subsection{Characterization techniques:}




\subsubsection{Raman spectroscopy:}

A SENTERRA Raman spectrometer with a grating of 600 lines per $\mathrm{mm}$ and a laser wavelength of $532 \mathrm{~nm}$ at a very low laser power level $(<1 \mathrm{~mW})$ to avoid any heating effect, was used to characterize the exfoliated graphite obtained via sonication. This technique is considered a reliable and quick method to characterize graphene-based materials ${ }^{22}$. A minimum of 50 points per sample were analyzed by RAMAN in order to obtain the corresponding average values.

\subsubsection{Thermogravimetric analysis (TGA):}

TG curve represents the evolution of the loss weight of a sample as a function of the temperature and/or time. The exfoliated graphite samples combustion were carried out in a TGA device (TGA-DSC 1, METTLER TOLEDO). Samples were heated from 30 to $1000{ }^{\circ} \mathrm{C}$ at a heating rate of $10{ }^{\circ} \mathrm{C} / \mathrm{min}$ under a reactive atmosphere of $21 \%$ of $\mathrm{O}_{2}$ and $79 \%$ of $\mathrm{N}_{2}$. Sample weight was kept at $8 \mathrm{mg}$ and a constant flow rate of $100 \mathrm{Nml} / \mathrm{min}$ was used during the experiments.

\section{Results:}

Hansen Solubility Parameters (HSP) were determined in order to know the affinity and solubility between different solvents and graphene layers. In this way, an Excel-VBA application was designed to calculate each Hansen Solubility Parameter, taking into account the value of that one for graphite and each studied solvent (Table 1).

Table 1: Hansen solubility parameters

\begin{tabular}{|l|l|l|l|}
\hline COMPONENT & $\delta_{\mathrm{H}\left(\mathrm{MPa}^{1 / 2}\right)}$ & $\delta_{\mathrm{D}\left(\mathrm{MPa}^{1 / 2}\right)}$ & $\delta_{\mathrm{P}}\left(\mathrm{MPa}^{1 / 2}\right)$ \\
\hline GRAPHENE & 7.7 & 18 & 9.3 \\
\hline WATER & 16.9 & 18.1 & 17.1 \\
\hline ACETONE & 7 & 15.5 & 10.4 \\
\hline ETHANOL & 19.4 & 15.8 & 8.8 \\
\hline 1-BUTANOL & 15.8 & 16 & 5.7 \\
\hline 2-BUTANOL & 4.5 & 15.5 & 5.7 \\
\hline
\end{tabular}

Table 2 shows the Hansen Solubility Parameters corresponding to different aqueous and organic mixtures. A significant increase in solubility is obtained by minimizing $R a$ value ( $R a<5.6$ $\mathrm{MPa}^{0.5}$ ) and maximizing $\Gamma_{\mathrm{G}}$ value ${ }^{17}$ as a function of the mass fraction. In this way, the application was designed to show lighter colors for best solubility values and darker colors for worst solubility values. Following these requirements, in Table 2 is possible to observe that mixture
water/2-Butanol has the I€ower Ra value; however, it is an immiscible mixture. Therefore, the optimal mixture for aqueous solvents corresponds to water/acetone with a mass fraction of acetone equal to 0.7 (Figure 1.a.). In addition, it could be observed that, optimal organic mixture corresponds to 1-Butanol/2Butanol with a mass fraction of 0.5 for each solvent (Figure 1.b.). 
Table 2: Hansen solubility parameters for both binary aqueous and organic mixtures.

\begin{tabular}{|c|c|c|c|c|c|c|c|c|c|c|c|c|c|}
\hline \multicolumn{6}{|c|}{ AQUEOUS SOLVENTS } & \multicolumn{8}{|c|}{ ORGANIC SOLVENTS } \\
\hline \multicolumn{2}{|c|}{ BINARY MIXTURE } & \multicolumn{2}{|c|}{ Water/Acetone } & \multicolumn{2}{|c|}{ Water/Ethanol } & \multicolumn{2}{|c|}{ BINARY MIXTURE } & \multicolumn{2}{|c|}{ 1-Butanol/2-Butanol } & \multicolumn{2}{|c|}{ Acetone/Ethanol } & \multicolumn{2}{|c|}{ 1-Butanol/Acetone } \\
\hline \multicolumn{2}{|c|}{ SAMPLE TYPE } & \multicolumn{2}{|c|}{ Miscible } & \multicolumn{2}{|c|}{ Miscible } & \multicolumn{2}{|c|}{ SAMPLE TYPE } & \multicolumn{2}{|c|}{ Miscible } & \multicolumn{2}{|c|}{ Miscible } & \multicolumn{2}{|c|}{ Miscible } \\
\hline \multicolumn{2}{|c|}{ MASS FRACTION } & \multicolumn{2}{|c|}{ Graphene } & \multicolumn{2}{|c|}{ Graphene } & \multicolumn{2}{|c|}{ MASS FRACTION } & \multicolumn{2}{|c|}{ Graphene } & \multicolumn{2}{|c|}{ Graphene } & \multicolumn{2}{|c|}{ Graphene } \\
\hline$w_{1}$ & $w_{2}$ & $\mathbf{R}_{\mathrm{a}}$ & $\Gamma_{G}$ & $R_{a}$ & $\Gamma_{G}$ & $w_{1}$ & $w_{2}$ & $\mathbf{R}_{\mathrm{a}}$ & $\Gamma_{G}$ & $R_{a}$ & $\Gamma_{G}$ & $R_{a}$ & $\Gamma_{G}$ \\
\hline 0 & 1 & 11,447 & $5,92 \mathrm{E}-15$ & 11,447 & $5,92 \mathrm{E}-15$ & 0 & 1 & 7,338 & $1,43 E-06$ & 10,244 & $4,04 \mathrm{E}-12$ & 6,237 & 5,98E-05 \\
\hline 0,1 & 0,9 & 10,067 & $9,94 \mathrm{E}-12$ & 10,835 & $1,79 \mathrm{E}-13$ & 0,1 & 0,9 & 6,492 & $2,65 \mathrm{E}-05$ & 9,18 & $7,07 \mathrm{E}-10$ & 5,593 & 4,01E-04 \\
\hline 0,2 & 0,8 & 8,826 & $3,48 \mathrm{E}-09$ & 10,352 & $2,32 \mathrm{E}-12$ & 0,2 & 0,8 & 5,745 & 2,61E-04 & 8,169 & $5,69 \mathrm{E}-08$ & 5,057 & 1,67E-03 \\
\hline 0,3 & 0,7 & 7,741 & 3,12E-07 & 9,994 & $1,43 \mathrm{E}-11$ & 0,3 & 0,7 & 5,138 & $1,36 \mathrm{E}-03$ & 7,231 & $2,10 \mathrm{E}-06$ & 4,668 & 4,31E-03 \\
\hline 0,4 & 0,6 & 6,835 & $8,45 E-06$ & 9,756 & $4,63 \mathrm{E}-11$ & 0,4 & 0,6 & 4,727 & $3,75 \mathrm{E}-03$ & 6,402 & $3,55 \mathrm{E}-05$ & 4,468 & 6,80E-03 \\
\hline 0,5 & 0,5 & 6,139 & $8,09 \mathrm{E}-05$ & 9,629 & $8,59 \mathrm{E}-11$ & 0,5 & 0,5 & 4,566 & $5,46 \mathrm{E}-03$ & 5,726 & $2,75 \mathrm{E}-04$ & 4,487 & 6,52E-03 \\
\hline 0,6 & 0,4 & 5,683 & 3,12E-04 & 9,601 & $9,80 \mathrm{E}-11$ & 0,6 & 0,4 & 4,68 & 4,19E-03 & 5,266 & 9,75E-04 & 4,723 & 3,78E-03 \\
\hline 0,7 & 0,3 & 5,486 & $5,40 \mathrm{E}-04$ & 9,662 & $7,32 \mathrm{E}-11$ & 0,7 & 0,3 & 5,051 & $1,70 \mathrm{E}-03$ & 5,08 & $1,58 \mathrm{E}-03$ & 5,151 & $1,32 \mathrm{E}-03$ \\
\hline 0,8 & 0,2 & 5,54 & 4,66E-04 & 9,797 & 3,79E-11 & 0,8 & 0,2 & 5,63 & 3,62E-04 & 5,199 & $1,16 \mathrm{E}-03$ & 5,73 & 2,72E-04 \\
\hline 0,9 & 0,1 & 5,807 & $2,18 \mathrm{E}-04$ & 9,995 & $1,42 \mathrm{E}-11$ & 0,9 & 0,1 & 6,36 & $4,06 \mathrm{E}-05$ & 5,603 & $3,91 \mathrm{E}-04$ & 6,421 & 3,33E-05 \\
\hline 1 & 0 & 6,237 & 5,98E-05 & 10,244 & $4,04 \mathrm{E}-12$ & 1 & 0 & 7,195 & 2,39E-06 & 6,237 & $5,98 \mathrm{E}-05$ & 7,195 & 2,39E-06 \\
\hline \multicolumn{2}{|c|}{ BINARY MIXTURE } & \multicolumn{2}{|c|}{ Water/1-Butanol } & \multicolumn{2}{|c|}{ Water/2-Butanol } & \multicolumn{2}{|c|}{ BINARY MIXTURE } & 1-Butan & Ethanol & 2-Butan & ol/Ethanol & 2-Buta & nol/Acetone \\
\hline SAM & YPE & Immisci & & Immisci & & SAN & & Miscible & & Miscible & & Miscibl & \\
\hline MAS & CTION & Graphe & & Graphe & & MA: & IION & Graphe & & Graphe & & Graphe & ene \\
\hline$w_{1}$ & $w_{2}$ & $R_{a}$ & $\Gamma_{G}$ & $R_{a}$ & $\Gamma_{G}$ & $w_{1}$ & $w_{2}$ & $R_{a}$ & $\Gamma_{G}$ & $R_{a}$ & $\Gamma_{G}$ & $R_{a}$ & $\Gamma_{G}$ \\
\hline 0 & 1 & 11,447 & $5,92 \mathrm{E}-15$ & 11,447 & $5,92 \mathrm{E}-15$ & 0 & 1 & 10,244 & $4,04 \mathrm{E}-12$ & 10,244 & $4,04 \mathrm{E}-12$ & 6,237 & 5,98E-05 \\
\hline 0,1 & 0,9 & 10,281 & $3,35 \mathrm{E}-12$ & 9,45 & $2,01 \mathrm{E}-10$ & 0,1 & 0,9 & 9,887 & $2,44 \mathrm{E}-11$ & 8,916 & 2,34E-09 & 6,15 & 7,82E-05 \\
\hline 0,2 & 0,8 & 9,248 & $5,18 \mathrm{E}-10$ & 7,601 & $5,33 \mathrm{E}-07$ & 0,2 & 0,8 & 9,537 & $1,34 \mathrm{E}-10$ & 7,641 & \begin{tabular}{|l|}
$48 \mathrm{E}-07$ \\
\end{tabular} & 6,108 & $8,91 \mathrm{E}-05$ \\
\hline 0,3 & 0,7 & 8,363 & $2,55 \mathrm{E}-08$ & 5,936 & $1,49 \mathrm{E}-04$ & 0,3 & 0,7 & 9,196 & $6,60 \mathrm{E}-10$ & 6,457 & $2,98 \mathrm{E}-05$ & 6,111 & 8,83E-05 \\
\hline 0,4 & 0,6 & 7,642 & 4,56E-07 & 4,541 & 5,77E-03 & 0,4 & 0,6 & 8,865 & 2,94E-09 & 5,429 & 6,31E-04 & 6,16 & 7,60E-05 \\
\hline 0,5 & 0,5 & 7,103 & 3,33E-06 & 3,603 & $3,90 \mathrm{E}-02$ & 0,5 & 0,5 & 8,545 & $1,18 \mathrm{E}-08$ & 4,669 & 4,30E-03 & 6,254 & 5,66E-05 \\
\hline 0,6 & 0,4 & 6,759 & $1,10 \mathrm{E}-05$ & 3,391 & $5,64 \mathrm{E}-02$ & 0,6 & 0,4 & 8,24 & $4,25 \mathrm{E}-08$ & 4,327 & 9,27E-03 & 6,393 & 3,65E-05 \\
\hline 0,7 & 0,3 & 6,613 & $1,79 \mathrm{E}-05$ & 3,93 & $2,10 \mathrm{E}-02$ & 0,7 & 0,3 & 7,949 & $1,38 \mathrm{E}-07$ & 4,509 & 6,21E-03 & 6,574 & $2,03 \mathrm{E}-05$ \\
\hline 0,8 & 0,2 & 6,654 & $1,56 \mathrm{E}-05$ & 4,918 & $2,37 \mathrm{E}-03$ & 0,8 & 0,2 & 7,677 & 3,99E-07 & 5,164 & 1,27E-03 & 6,793 & 9,76E-06 \\
\hline 0,9 & 0,1 & 6,859 & 7,81E-06 & 6,095 & $9,25 \mathrm{E}-05$ & 0,9 & 0,1 & 7,425 & $1,04 \mathrm{E}-06$ & 6,149 & $7,84 \mathrm{E}-05$ & 7,049 & 4,03E-06 \\
\hline 1 & 0 & 7,195 & $2,39 \mathrm{E}-06$ & 7,338 & $1,43 E-06$ & 1 & 0 & 7,195 & $2,39 \mathrm{E}-06$ & 7,338 & 1,43E-06 & 7,338 & 1,43E-06 \\
\hline
\end{tabular}


a)
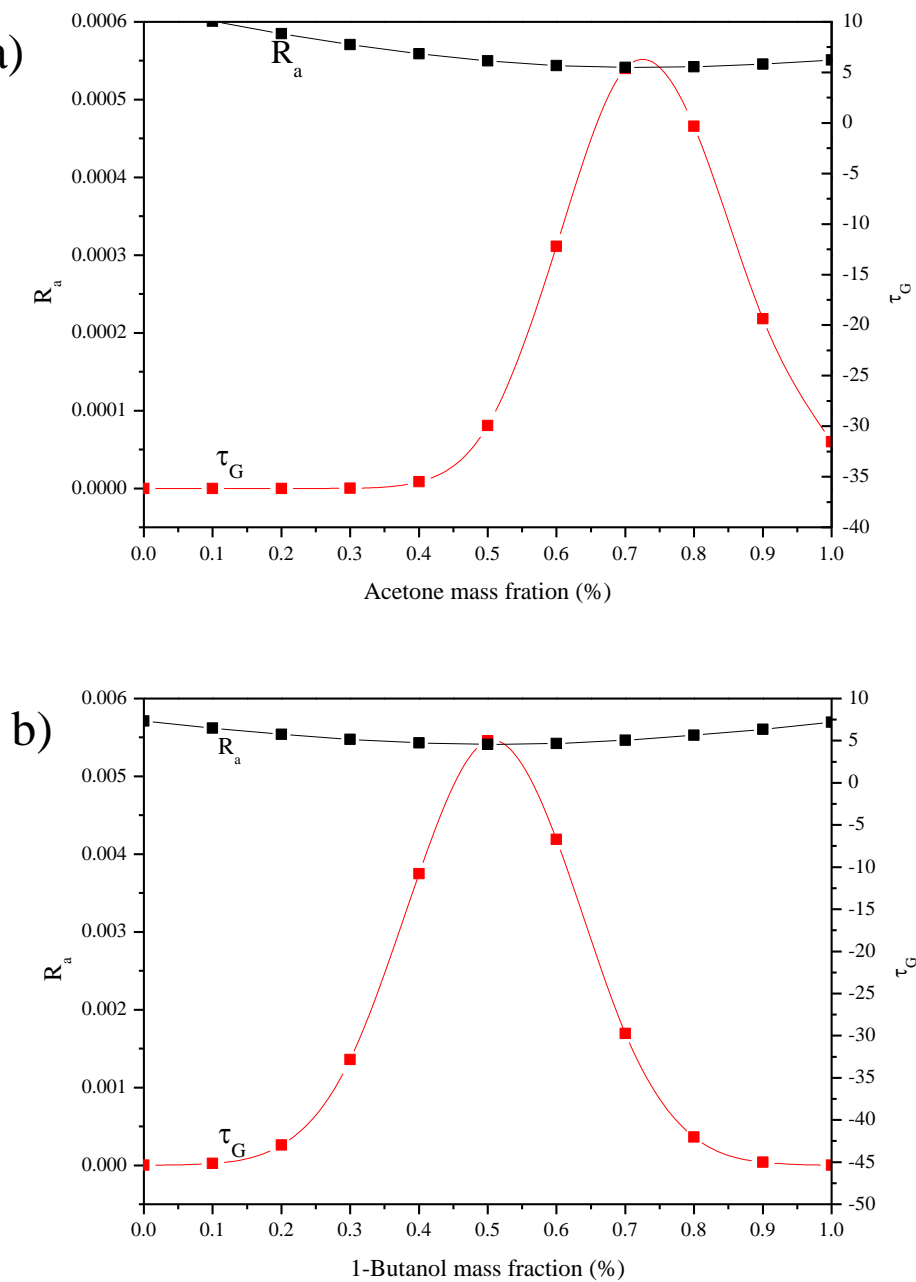

Figure 1: $R_{a} / \Gamma_{G}$ vs. solvent mass fraction: a) water/acetone mixture and, b) 1-Butanol mass mixture.

Once the best solvent mixtures were selected, it was carried out an in-depth study to analyze the influence of different operational parameters involved in sonication process: sonication temperature, sonication cycle, sonication amplitude and sonication time.

\section{Influence of the sonication temperature:}

In order to analyze how sonication temperature influences over the liquid phase exfoliation of graphite and the physical-chemical characteristics of the resulting product, different exfoliation experiments were carried out varying this parameter between 15 and $30^{\circ} \mathrm{C}$. The rest of parameters that could influence on the exfoliation process were kept constant in all those experiments (sonication amplitude: $30 \%$, sonication cycle: 1 and sonication time: 5 hours).

Figure 2 shows Raman spectra and the corresponding Raman parameters 23, 24 of graphite (raw material) and exfoliated graphite

samples obtained by sonication in both aqueous and organic solutions.

Three different peaks could be observed in the Raman spectrum of both graphite and exfoliated graphite. The first one (D peak), which is around $1350 \mathrm{~cm}^{-1}$, is related to the defects present in the sample. G peak, around $1650 \mathrm{~cm}^{-1}$, is due to the movement of two carbon atoms that are $\mathrm{sp}^{2}$ bonded. The position of this band may be affected by the pressure exerted on the sample, the doping or the temperature, while $\mathrm{G}$ intensity is less susceptible to these factors ${ }^{25}$. Besides these two, one additional peak arises from a two phonon double resonance Raman process, known as 2D band, appearing at around 2710 $\mathrm{cm}^{-1}$.

In general, 2D band corresponding to exfoliated samples can be identified as the typical signal arising for multilayer graphene and displacing to lower values of Raman Shift $\left(\mathrm{cm}^{-1}\right)$ compared to 2D peak of graphite (Figure $2 \mathrm{~b}$ ). It is know that, 
M.P. Lavin-Lopez et al., IRJMSA, 2017; 1:5

the shape of the 2D Raman band can be used to determine the number of layers in the exfoliated graphene ${ }^{25}$. As observed in Figure 2b, 2D band of exfoliated graphite became symmetrical, comparing to that one of graphite, suggesting the successful exfoliation of graphite ${ }^{26}$.

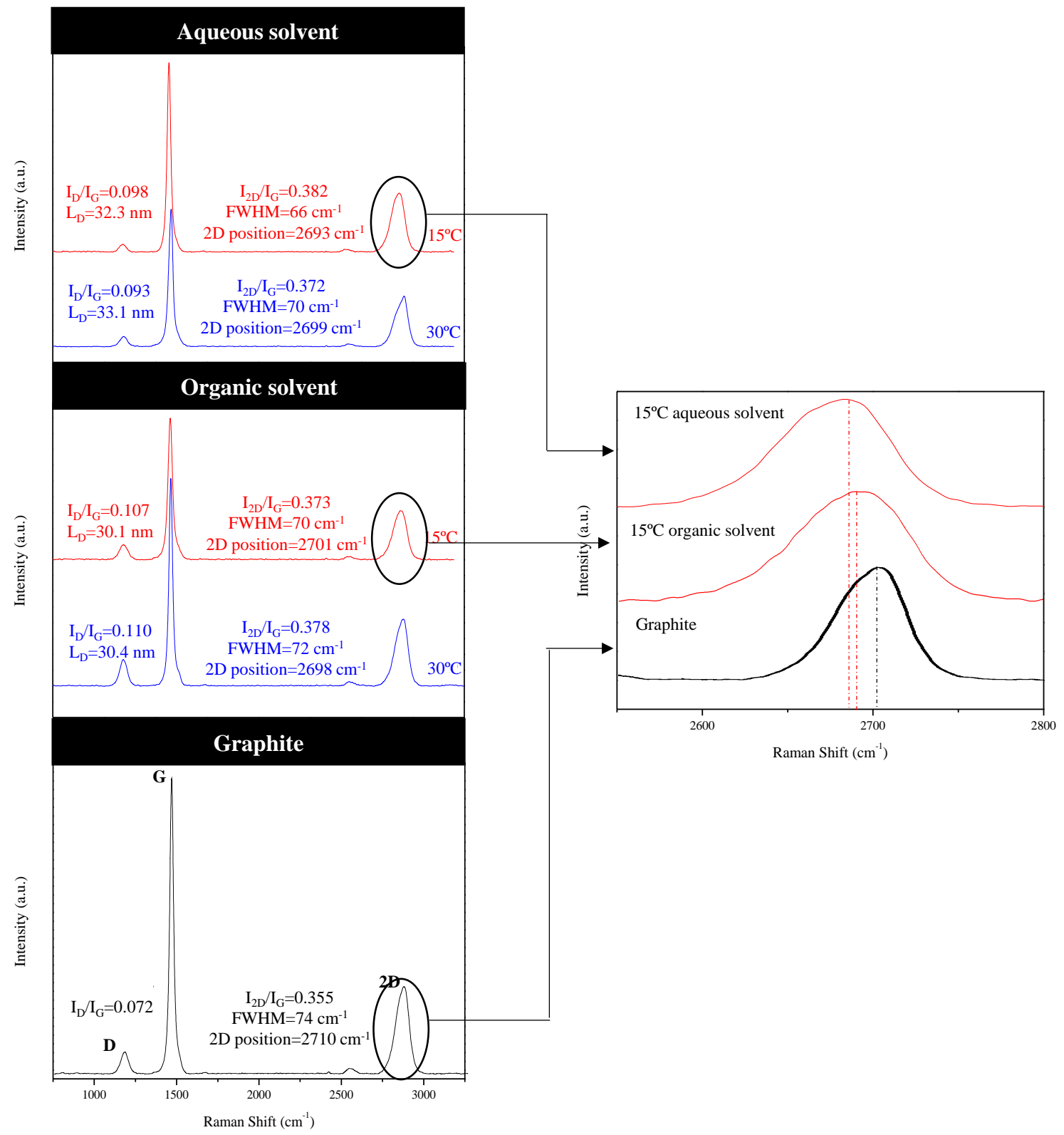

Figure 2: Influence of sonication temperature: a) Raman spectra corresponding to graphite and exfoliated graphite samples; b) magnified 2D bands.

(Sonication conditions: Temperature $=15-30^{\circ} \mathrm{C}$, cycle $=1$, Amplitude $=30 \%$, Time $=5$ hours)

In addition, for a thorough characterization of the samples, certain relationships derived from Raman spectrums should be taken into account. The intensity ratio between $\mathrm{D}$ and $\mathrm{G}$ bands $\left(\mathrm{I}_{\mathrm{D}} / \mathrm{IG}_{\mathrm{G}}\right)$ increases with an increase of the defects in the structure and depends on the size of the crystal plane 27 . This relationship increased from graphite to exfoliated graphite samples due to the shear forces that graphite experiment, which not only exfoliate but also breaks its layers, increasing the structural defects (note that the distance between defects $\left(L_{D}\right)$ decrease after exfoliation) ${ }^{28}$.

Other remarkable relationship is the intensity ratio between $2 D$ and $G$ peaks $\left(\mathrm{l}_{2 \mathrm{D}} / \mathrm{l}_{\mathrm{G}}\right)$ as, it can be used to compare the exfoliation degree among several samples. Comparing to graphite, it can be observed that $\mathrm{I}_{2 \mathrm{D}} / \mathrm{I}_{\mathrm{G}}$ values slightly increased for exfoliated graphite, highlighting the greater separation between graphene sheets. 
M.P. Lavin-Lopez et al., IRJMSA, 2017; 1:5

Another two characteristic RAMAN parameters in graphitic materials are FWHM (Full Width at Half Maximum) and 2D peak position ${ }^{18,29}$. The former is related to the lifetime of the excited stated and it is calculated as the difference of the Raman Shift $\left(\mathrm{cm}^{-1}\right)$ to the average height of the
Thermogravimetric analysis were performed to study the resistance of the exfoliated graphite samples to thermal degradation. Figure 3 shows TGA profiles and the corresponding DTG curves and, Table 3 the characteristic thermal degradation temperatures. TGA curve of

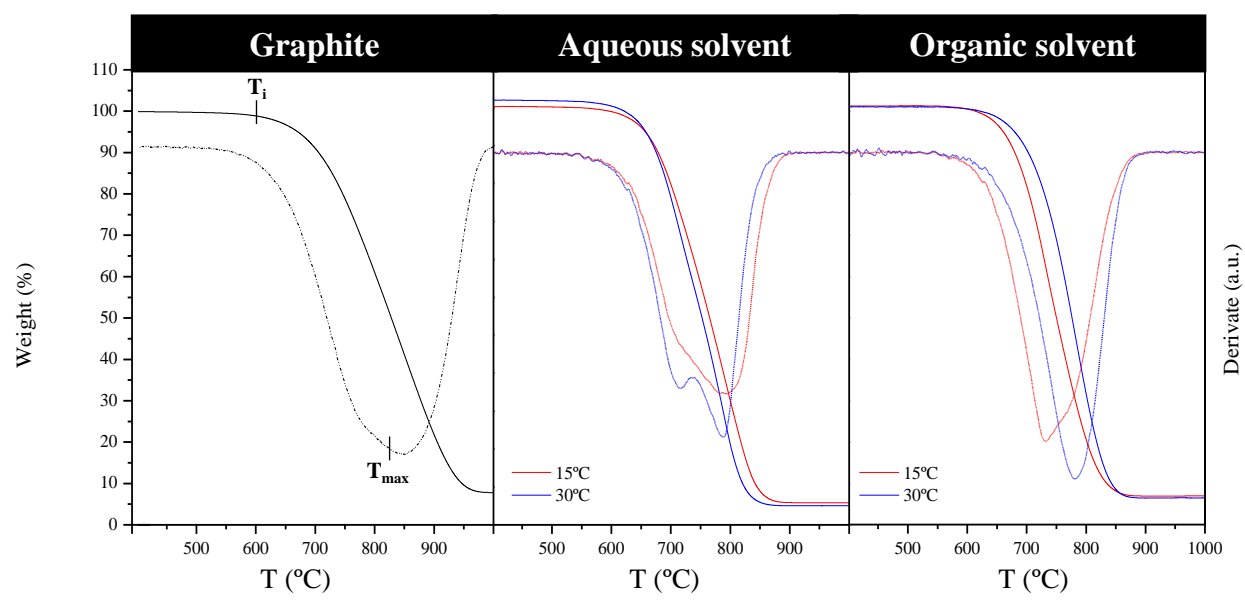

2D band. In general, both FWHM and 2D peak position, decreased after graphite exfoliation.

Comparing RAMAN results at different sonication temperatures, it could be deduced that, effectiveness of graphite exfoliation process was not substantially influenced by the sonication temperature regardless it is carried out using aqueous or organic solvents. graphite confirms its high thermal stability; i.e. no weight loss was observed until around $650 \stackrel{\circ}{\circ}$, temperature at which graphite begins to drastically degrade, being carbon continuously oxidized to $\mathrm{CO}_{2}{ }^{30}$. After exfoliation, a decrease of the thermal degradation resistance took place which has been attributed to the disorder increase confirmed by RAMAN analysis

Figure 3: Influence of sonication temperature: TGA and DTG curves of graphite and exfoliated samples. (Sonication conditions: Temperature $=15-30^{\circ} \mathrm{C}$, cycle $=1$, Amplitude $=30 \%$, Time $=5$ hours) Table 3: Influence of sonication temperature: Representative thermal degradation temperatures. (Sonication conditions: Temperature $=15-30^{\circ} \mathrm{C}$, cycle $=1$, Amplitude $=30 \%$, Time $=5$ hours)

\begin{tabular}{|c|c|c|c|c|c|}
\hline & \multirow{2}{*}{ GRAPHITE } & \multicolumn{2}{|c|}{ AQUEOUS SOLVENT } & \multicolumn{2}{|c|}{ ORGANIC SOLVENT } \\
\hline & & $15^{\circ} \mathrm{C}$ & $30^{\circ} \mathrm{C}$ & $15^{\circ} \mathrm{C}$ & $30^{\circ} \mathrm{C}$ \\
\hline $\mathrm{T}_{\mathrm{i}}\left({ }^{\circ} \mathrm{C}\right)$ & 600 & 565 & 570 & 560 & 550 \\
\hline$T_{\max }\left({ }^{\circ} \mathrm{C}\right)$ & 837 & 770 & 780 & 750 & 780 \\
\hline
\end{tabular}

$T_{i}:$ Initial thermal degradation temperature

$T_{\max }$ : Temperature of the máximum degradation rate

Based on the obtained results, it is possible to assert that, sonication temperature is not a significant parameter on the graphite exfoliation process in the studied conditions. Thus, $15^{\circ} \mathrm{C}$ was selected as optimum sonication temperature for both aqueous and organic solvents to carry out the following experiments.
The influence of the sonication cycle was studied by varying it between 0.5 and 1 , maintaining constant the rest of parameters. Table 4 summarizes the most important RAMAN spectroscopy parameters of exfoliated graphite samples prepared at different sonication cycles for both aqueous and organic solvents.

\section{Influence of the sonication cycle:}


M.P. Lavin-Lopez et al., IRJMSA, 2017; 1:5

Table 4: Influence of sonication cycle: Raman spectroscopy parameters and thermal degradation temperatures corresponding to exfoliated samples.

(Sonication conditions: Temperature $=15^{\circ} \mathrm{C}$, cycle $=0.5-1$, Amplitude $=30 \%$, Time $=5$ hours)

\begin{tabular}{|c|c|c|c|c|}
\hline & \multicolumn{2}{|c|}{ AQUEOUS SOLVENT } & \multicolumn{2}{|c|}{ ORGANIC SOLVENT } \\
\hline & 0.5 & 1 & 0.5 & 1 \\
\hline $\mathbf{I D} / \mathbf{I G}_{\mathrm{G}}$ & 0.078 & 0.098 & 0.081 & 0.107 \\
\hline$I_{2 D} / I_{G}$ & 0.359 & 0.382 & 0.367 & 0.373 \\
\hline FWHM $\left(\mathrm{cm}^{-1}\right)$ & 73 & 66 & 74 & 70 \\
\hline $\begin{array}{ll}\text { 2D } & \text { POSITION } \\
\left(\mathrm{cm}^{-1}\right) & \\
\end{array}$ & 2698 & 2693 & 2705 & 2701 \\
\hline LD (RAMAN) & 36.1 & 32.3 & 35.5 & 30.1 \\
\hline$T_{i}\left({ }^{\circ} \mathrm{C}\right)$ & 594 & 565 & 583 & 560 \\
\hline$T_{\max }(\stackrel{\circ}{-C})$ & 776 & 770 & 772 & 750 \\
\hline
\end{tabular}

$T_{i}:$ Initial thermal degradation temperature

$T_{\max }$ : Temperature of the máximum rate of degradation

LD: Distance between defects

From RAMAN results can be deduced that, a decrease in the sonication cycle from 1 to 0.5 , causes slight structural changes in the resulting exfoliated material. Thus, it can be observed that $\mathrm{I}_{2 \mathrm{D} / \mathrm{IG}}$ parameter slightly decrease and, FWHM value and 2D peak position increases, indicating that exfoliation process is more effective at high sonication cycles. Nevertheless, ID/lg ratio increase with the increase of the sonication cycle proves that, the higher efficiency in the exfoliation process also favored the defect formation (as was also evidence for the lower distance between defects, $\left.L_{D}\right)^{31}$.

By its part, thermogravimetric analysis results (Table 4) agree with those results obtained by RAMAN spectroscopy. Thus, exfoliated graphite samples prepared at the lowest sonication cycle, showed a lightly higher resistance to thermal degradation due to its lower exfoliation degree and as consequence, the lower amount of defects in it structure.

Based on the obtained results, a sonication cycle equal to 1 was selected for both aqueous and organic solvents to carry out the following experiments.

\section{Influence of the sonication amplitude:}

The influence of the sonication amplitude was studied by varying it between 30 and $90 \%$, maintained constant the rest of parameters.

Table 5 shows the characteristic RAMAN parameters of exfoliated graphite samples prepared during the study of the different sonication amplitudes for both aqueous and organic solvents.

Table 5: Influence of sonication amplitude: Raman spectroscopy parameters and thermal degradation temperatures corresponding to exfoliated samples.

(Sonication conditions: Temperature $=15^{\circ} \mathrm{C}$, cycle $=1$, Amplitude $=30-90 \%$, Time $=5$ hours)

\begin{tabular}{|c|c|c|c|c|c|c|}
\hline & \multicolumn{3}{|c|}{$\begin{array}{l}\text { AQUEOUS } \\
\text { SOLVENT }\end{array}$} & \multicolumn{3}{|c|}{$\begin{array}{l}\text { ORGANIC } \\
\text { SOLVENT }\end{array}$} \\
\hline & 30 & 60 & 90 & 30 & 60 & 90 \\
\hline $\mathrm{ID}_{\mathrm{D}} / \mathrm{IG}_{\mathrm{G}}$ & $\begin{array}{l}0.09 \\
8\end{array}$ & 0.107 & 0.107 & 0.107 & 0.116 & 0.116 \\
\hline $\mathrm{I}_{2 \mathrm{D}} / \mathrm{IG}$ & $\begin{array}{l}0.38 \\
2\end{array}$ & 0.370 & 0.366 & 0.373 & 0.371 & 0.364 \\
\hline FWHM $\left(\mathrm{cm}^{-1}\right)$ & 66 & 82 & 70 & 70 & 77 & 77 \\
\hline $\begin{array}{l}\text { 2D POSITION }\left(\mathrm{cm}^{-}\right. \\
\text {1) }\end{array}$ & $\begin{array}{l}269 \\
3\end{array}$ & 2699 & 2700 & 2701 & 2699 & 2699 \\
\hline LD RAMAN & 32.3 & 30.9 & 30.9 & 30.1 & 29.6 & 29.6 \\
\hline
\end{tabular}


M.P. Lavin-Lopez et al., IRJMSA, 2017; 1:5

\begin{tabular}{|l|l|l|l|l|l|l|}
\hline $\mathbf{T}_{\mathbf{i}}\left({ }^{\circ} \mathbf{C}\right)$ & 565 & 565 & 568 & 560 & 518 & 522 \\
\hline $\mathbf{T}_{\max }\left({ }^{\circ} \mathbf{C}\right)$ & 770 & 727 & 711 & 750 & 748 & 750 \\
\hline
\end{tabular}

$\mathrm{T}_{\mathrm{i}}$ : Initial thermal degradation temperature

$T_{\max }$ : Temperature of the máximum rate of degradation

LD: Distance between defects

Obtained results suggests that an increase in the sonication waves amplitude, does not favor the graphite exfoliation process, regardless of the used solvent mixture. Thus, exfoliation process was favored for a sonication amplitude of $30 \%$ because of the slightly increase between 2D and $G$ peaks intensities and, the decrease of FWHM

Figure 4 shows TGA and DTG curves and, Table 5 the characteristic thermal degradation parameter, related with the decrease of the number of graphene layers. Once more, defects, related to ID/lG parameter, lightly increased with an increase of the sonication amplitude. Nevertheless, those defects are not associated to a better graphite exfoliation but for a graphite crystal breakage ${ }^{32}$.

temperatures for samples obtained at $30 \%, 60 \%$ and $90 \%$ of sonication amplitude.

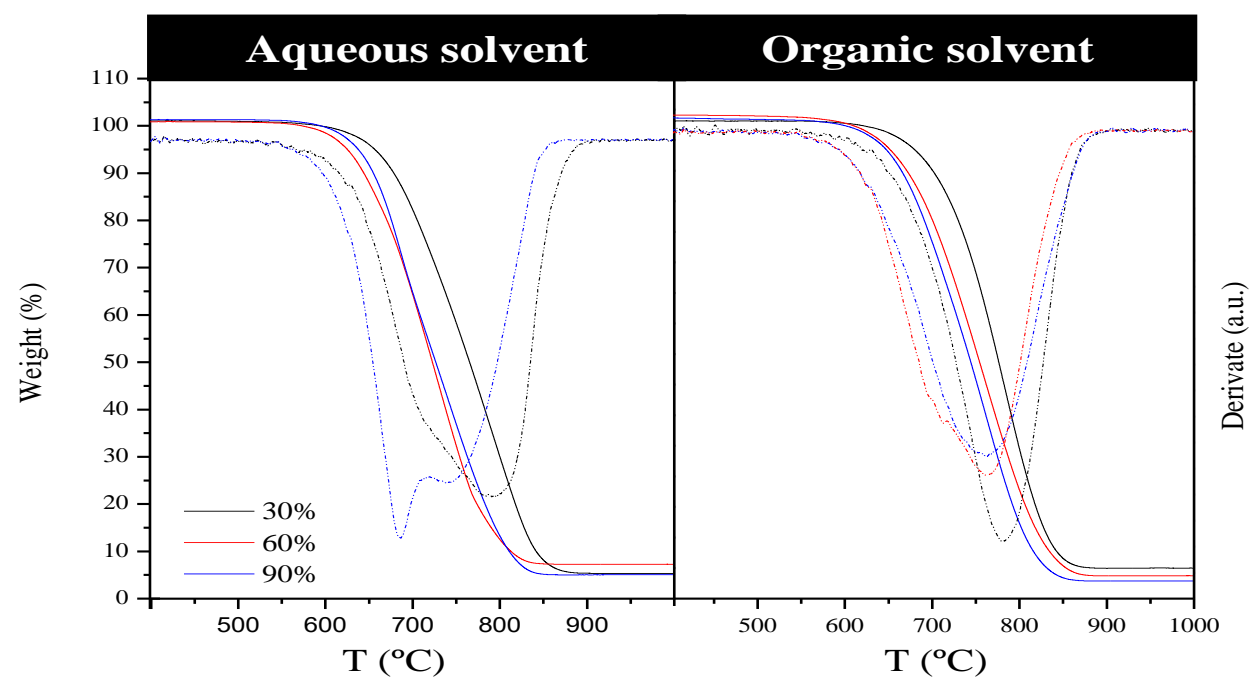

Figure 4: Influence of sonication amplitude: TGA and DTG curves of exfoliated samples. (Sonication conditions: Temperature $=15^{\circ} \mathrm{C}$, cycle $=1$, Amplitude $=30-90 \%$, Time $=5$ hours)

From thermogravimetric analysis results, at higher sonication amplitudes it was observed a lightly decrease of the thermal resistance which is not associated to a better graphite exfoliation as commented before. The lower thermal resistance could be associated to graphite crystals breakage in a greater extension.

Based on the obtained results, a sonication amplitude of $30 \%$ was selected to carry out the following experiments.

\section{Influence of the sonication time:}

Optimization of sonication time is critical because it is considered a key parameter with a strong influence over the defect concentration of exfoliated products ${ }^{15}$. It has been demonstrated that, sonication time strongly affects the final size of carbon nanotubes flakes 33 and consequently, its quality ${ }^{7}$. For this reason, graphite dispersions were sonicated at different times $(2.5,5,12,24$ and, 48 h) maintaining constant the rest of sonication parameters.

Figure 6 (a) shows ID/lg ratio and LD parameter variations at different sonication times and, Figure 6 (b) the $\mathrm{I}_{2 \mathrm{D}} / \mathrm{IG}_{\mathrm{G}}$ variation vs. sonication time. As before, 2D peak can be identified as the typical signal arising for multilayer graphene, being $D$ and $G$ bands well resolved for all samples (not shown). The quantity of defects, related to $\mathrm{ID} / \mathrm{lg}_{\mathrm{G}}$ ratio, increased with the 
M.P. Lavin-Lopez et al., IRJMSA, 2017; 1:5

increasing of sonication time for both aqueous and organic solvents, indicating an increase in the defect density ${ }^{34}$. By its part, inspection of average 2D position or FWHM (2D) for samples exfoliated during different sonication times did not show any clear trend.

It has been demonstrated that, $I_{D} / I_{G}$ ratio correlation with full width at half-maximum (FWHM) of G band, provides information about the origin of $D$ band ${ }^{34}$. This means that, if $D$ band changes are due to edge defects or bulk defects thus, an $\mathrm{ID} / \mathrm{lg}$ ratio increase can be associated to either bulk or edge defects while, FWHM (G) increase, is only due to bulk disorder. Table 6 check the correlation between the amount of disorder as quantified by $\mathrm{ID} / \mathrm{I}_{\mathrm{G}}$ ratio and, FWHM of the G band values at different sonication times. As observed, FWHM (G) begins to substantially increase to sonication times above 5 hours, indicating that predominates bulk defects formation (in contrast to edge defects) which, has been attributed to the cavitation that takes place during sonication 24.

Finally, thermogravimetric analysis confirms the decrease of thermal degradation resistance of exfoliated graphite as consequence of the defect formation on its structure at higher sonication times (Table 7).

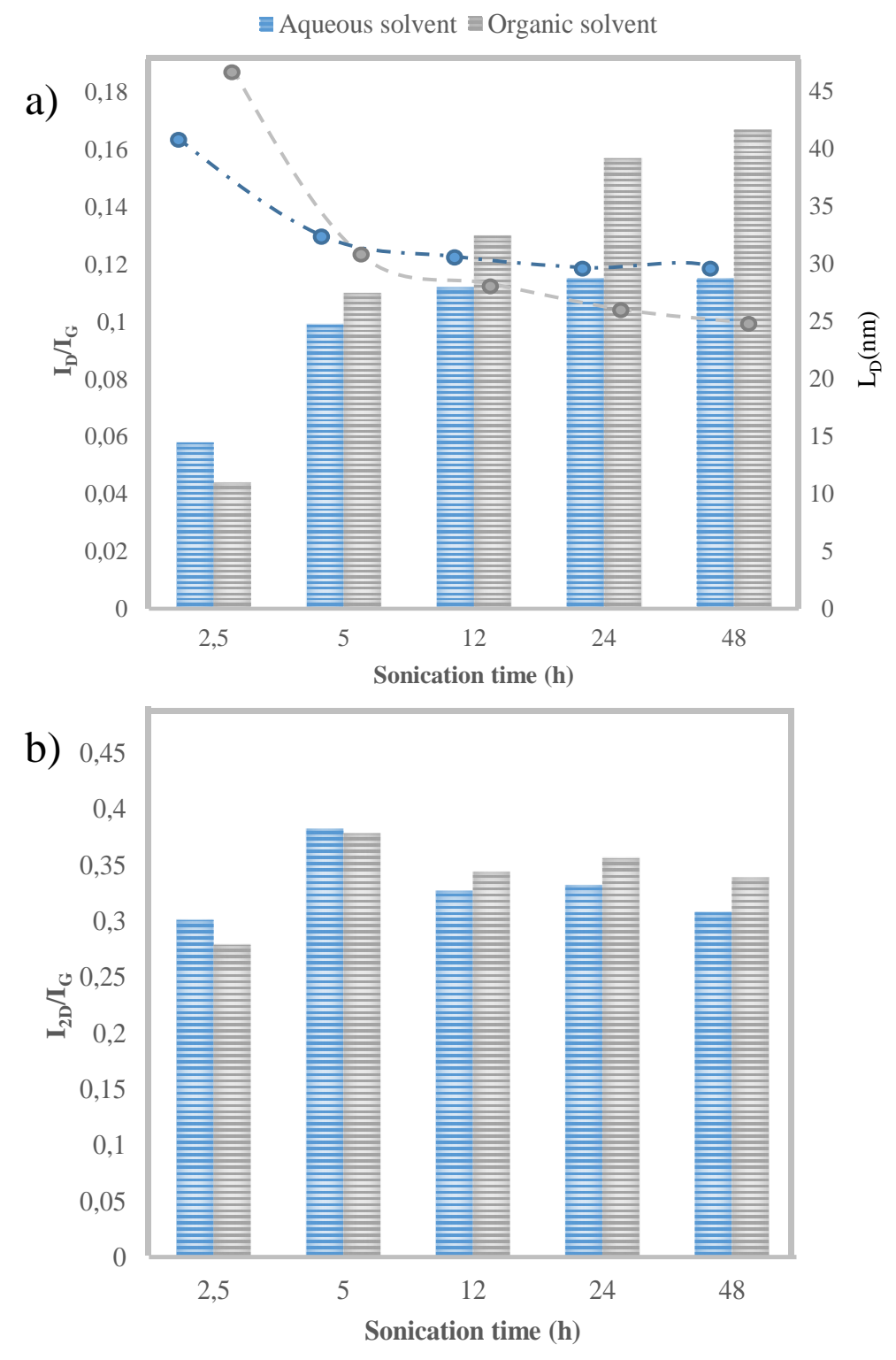

Figure 6: Influence of sonication time: a) $I_{D} / I_{G}$ and $L_{D}$ values and, b) $I_{2 D} / I_{G}$ variation vs. sonication time.

(Sonication conditions: Temperature $=15^{\circ} \mathrm{C}$, cycle $=1$, Amplitude $=30 \%$, Time $=2.5-48$ hours) 
M.P. Lavin-Lopez et al., IRJMSA, 2017; 1:5

Table 6: Influence of sonication time: $\mathrm{I}_{\mathrm{D}} / \mathrm{I}_{\mathrm{G}}$ and $\mathrm{FWHM}(\mathrm{G})$ variation with sonication time. (Sonication conditions: Temperature $=15^{\circ} \mathrm{C}$, cycle $=1$, Amplitude $=30 \%$, Time $=2.5-48$ hours)

\begin{tabular}{|c|c|c|c|c|c|c|}
\hline \multicolumn{2}{|c|}{ SONICATION TIME $(\mathrm{h})$} & $\mathrm{h}$ & h & $\mathrm{h}$ & h & 1 \\
\hline \multirow{2}{*}{$\begin{array}{l}\text { AQUEOUS } \\
\text { SOLVENT }\end{array}$} & $\begin{array}{l}\begin{array}{l}\text { FWHM } \\
\left(\mathrm{cm}^{-1}\right)\end{array}\end{array} \quad$ G $\quad p$ & 20 & 20 & 21 & 23 & 23 \\
\hline & $\mathrm{ID} / \mathrm{lG}$ & & & & & \\
\hline \multirow{2}{*}{$\begin{array}{l}\text { ORGANIC } \\
\text { SOLVENT }\end{array}$} & \begin{tabular}{|l|l|}
$\begin{array}{l}\text { FWHM } \\
\left(\mathrm{cm}^{-1}\right)\end{array}$ \\
\end{tabular} & 18 & 18 & 20 & 21 & 24 \\
\hline & & & & & & \\
\hline
\end{tabular}

Table 7: Influence of sonication time: Representative thermal degradation temperatures. (Sonication conditions: Temperature $=15^{\circ} \mathrm{C}$, cycle $=1$, Amplitude $=30 \%$, Time $=5-48$ hours)

\begin{tabular}{|c|c|c|c|}
\hline & & $\mathrm{T}_{\mathrm{i}}\left({ }^{\circ} \mathrm{C}\right)$ & $\mathrm{T}_{\max }\left({ }^{\circ} \mathbf{C}\right)$ \\
\hline \multirow{5}{*}{$\begin{array}{l}\text { AQUEOUS } \\
\text { SOLVENT }\end{array}$} & $2.5 \mathrm{~h}$ & 590 & 829 \\
\hline & $5 \mathrm{~h}$ & 565 & 770 \\
\hline & $12 \mathrm{~h}$ & 546 & 752 \\
\hline & $24 \mathrm{~h}$ & 538 & 713 \\
\hline & $48 \mathrm{~h}$ & 540 & 714 \\
\hline \multirow{5}{*}{$\begin{array}{l}\text { ORGANIC } \\
\text { SOLVENT }\end{array}$} & $2.5 \mathrm{~h}$ & 582 & 812 \\
\hline & $5 \mathrm{~h}$ & 560 & 750 \\
\hline & $12 \mathrm{~h}$ & 548 & 732 \\
\hline & $24 \mathrm{~h}$ & 530 & 719 \\
\hline & $48 \mathrm{~h}$ & 530 & 718 \\
\hline
\end{tabular}

$T_{i}:$ Initial thermal degradation temperature

$T_{\max }$ : Temperature of the máximum rate of degradation

\section{CONCLUSIONS:}

Two different solvent mixtures, both aqueous and organic ones, were used in graphite liquid phase exfoliation. These solvent mixtures were selected through a detailed study of Hansen Solubility Parameters. Different operational sonication parameters (sonication temperature, cycle, amplitude and time) were studied in detail in order to analyze their influence over the exfoliation process. Exfoliated graphite obtained after different sonication conditions were further characterized by RAMAN spectroscopy and thermogravimetric techniques. Obtained results showed that, among all the studied sonication parameters, temperature is the most important one due to its influence over the final exfoliated product characteristics. Thus, it was evidenced the defect formation at higher sonication times, being dominant the growth of bulk defects in the structure of exfoliated samples at sonication times above 5 hours. As consequence, a careful tuning of the sonication parameters is necessary in order to obtain exfoliated samples with low disorder.

\section{REFERENCES:}

1. A. K. Geim, K. S. Novoselov, Nat. Mater. 6, 183 (2007).

2. M. P. Lavin-Lopez, J. L. Valverde, L. SanchezSilva, A. Romero, Ind. Eng. Chem. Res. 55, 845 (2016).

3. Y. Hernandez, V. Nicolosi, M. Lotya, F. M. Blighe, Z. Sun, S. De, I. T. McGovern, B. Holland, M. Byrne, Y. K. Gun'ko, J. J. Boland, P. Niraj, G. Duesberg, S.
Krishnamurthy, R. Goodhue, J. Hutchison, V. Scardaci, A. C. Ferrari, J. N. Coleman, Nature nanotechnology. 3, 563 (2008).

4. M. Lotya, Y. Hernandez, P. J. King, R. J. Smith, V. Nicolosi, L. S. Karlsson, F. M. Blighe, S. De, W. Zhiming, I. T. McGovern, G. S. Duesberg, J. N. Coleman, J. Am. Chem. Soc. 131, 3611 (2009). 
M.P. Lavin-Lopez et al., IRJMSA, 2017; 1:5

5. R. S. Edwards, K. S. Coleman, Nanoscale. 5, 38 (2013); J. Xu, D. K. Dang, V. T. Tran, X. Liu, J. S. Chung, S. H. Hur, W. M. Choi, E. J. Kim, P. A. Kohl, J. Colloid Interface Sci. 418, 37 (2014).

6. J. L. V. M.P. Lavin-Lopez, L. Sanchez-Silva and A. Romero Industrial\&Engineering Chemistry Research. 55, 845 (2016).

7. A. Ciesielski, P. Samorì, Chemical Society Reviews. 43, 381 (2014).

8. C. Yeon, S. J. Yun, K. S. Lee, J. W. Lim, Carbon. 83, 136 (2015).

9. M. M. Hossain, O. K. Park, J. R. Hahn, B. C. Ku, Mater. Lett. 123, 90 (2014).

10. L. Zhu, X. Zhao, Y. Li, X. Yu, C. Li, Q. Zhang, Mater. Chem. Phys. 137, 984 (2013).

11. M. Yi, Z. Shen, S. Ma, X. Zhang, J. Nanopart. Res. 14, (2012).

12. W. Du, X. Jiang, L. Zhu, J. Mater. Chem. A. 1, 10592 (2013).

13. P. M. Carrasco, S. Montes, I. García, M. Borghei, H. Jiang, I. Odriozola, G. Cabañero, V. Ruiz, Carbon. 70, 157 (2014).

14. A. B. Bourlinos, V. Georgakilas, R. Zboril, T. A. Steriotis, A. K. Stubos, C. Trapalis, Solid State Commun. 149, 2172 (2009); S. Vadukumpully, J. Paul, S. Valiyaveettil, Carbon. 47, 3288 (2009); M. Lotya, P. J. King, U. Khan, S. De, J. N. Coleman, ACS Nano. 4, 3155 (2010); L. Guardia, M. J. Fernández-Merino, J. I. Paredes, P. Solís-Fernández, S. Villar-Rodil, A. Martínez-Alonso, J. M. D. Tascón, Carbon. 49, 1653 (2011).

15. U. Khan, A. O'Neill, M. Lotya, S. De, J. N. Coleman, Small. 6, 864 (2010).

16. A. B. Bourlinos, V. Georgakilas, R. Zboril, T. A. Sterioti, A. K. Stubos, Small. 5, 1841 (2009).

17. S. A. C. M. Hansen, Hansen Solubility Parameters in Practice. Hansen-Solubility; C. M. Hansen, Hansen Solubility Parameters: A User's Handbook, Second Edition. CRC Press: 2007.

18. M. Yi, Z. Shen, X. Zhang, S. Ma, J. Phys. D: Appl. Phys. 46, (2013).

19. J. S. Y. Chia, M. T. T. Tan, P. S. Khiew, J. K. Chin, H. Lee, D. C. S. Bien, C. W. Siong, Chem. Eng. J. 249, 270 (2014).

20. V. Alzari, V. Sanna, S. Biccai, T. Caruso, A. Politano, N. Scaramuzza, M. Sechi, D. Nuvoli, R. Sanna, A. Mariani, Composites Part B: Engineering. 60, 29 (2014).
21. D. Tasis, K. Papagelis, P. Spiliopoulos, C. Galiotis, Mater. Lett. 94, 47 (2013).

22. K. N. Kudin, B. Ozbas, H. C. Schniepp, R. K. Prud'homme, I. A. Aksay, R. Car, Nano Lett. 8, 36 (2008); A. Kaniyoor, S. Ramaprabhu, AIP Adv. 2, (2012).

23. B. Puangbuppha, P. Limsuwan, $P$. Asanithi In Non-chemically functionalized graphene exfoliated from graphite in water using ultrasonic treatment, 3rd International Science, Social Science, Engineering and Energy Conference 2011, I-SEEC 2011, Nakhon Pathom, Nakhon Pathom, 2012; pp 1094; J. Xu, Dang, D. K., Tran, V. T., Liu, X., Chung, J. S., Hur, S. H., Choi, W. M., Kim, E. J. y Kohl, P. A., Journal of Colloid and Interface Science. 418, 37 (2014); M. M. Hossain, Park, O. K., Hahn, J. R. y Ku, B. C., Materials Letters. 123, 90 (2014).

24. P. M. Carrasco, Montes, S., García, I., Borghei, M., Jiang, H., Odriozola, I., Cabañero, G. y Ruiz, V., Carbon. 70, 157 (2014).

25. A. C. Ferrari, Solid State Commun. 143, 47 (2007).

26. M. Noroozi, A. Zakaria, S. Radiman, Z. A. Wahab, PLoS ONE. 11, (2016).

27. R. J. Nemanich, S. A. Solin, Physical Review B. 20, 392 (1979).

28. Z.-S. W. Khaled Parvez, Rongjin Li, Xianjie Liu, Robert Graf, Xinliang Feng, Klaus Müllen, Journal of American Chemical Society. 136, 6083 (2014).

29. Y. Y. Wang, Z. H. Ni, T. Yu, Z. X. Shen, H. M. Wang, Y. H. Wu, W. Chen, A. T. S. Wee, J. Phys. Chem. C. 112,10637 (2008).

30. L. M. Viculis, J. J. Mack, O. M. Mayer, H. T. Hahn, R. B. Kaner, J. Mater. Chem. 15, 974 (2005); W. Fu, J. Kiggans, S. H. Overbury, V. Schwartz, C. Liang, Chem. Commun. 47, 5265 (2011).

31. P. M. Carrasco, S. Montes, I. García, M. Borghei, H. Jiang, I. Odriozola, G. Cabañero, V. Ruiz, Carbon. 70, 157 (2014).

32. A. V. Alaferdov, Gholamipour-Shirazi, A., Canesqui, M. A., Danilov, Y. A. and Moshkalev, S. A., Carbon. 69, 525 (2014).

33. F. Hennrich, R. Krupke, K. Arnold, J. A. R. Stütz, S. Lebedkin, T. Koch, T. Schimmel, M. M. Kappes, J. Phys. Chem. B. 111, 1932 (2007).

34. M. V. Bracamonte, G. I. Lacconi, S. E. Urreta, L. E. F. Foa Torres, The Journal of Physical Chemistry C. 118, 15455 (2014).

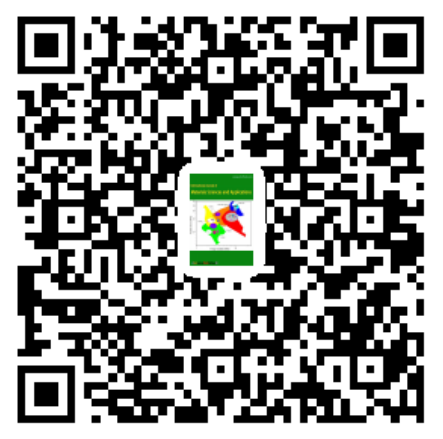

